\title{
Double Trouble- Endodontic Management of a Doubly Curved Root Canal System: A Case Report
}

\author{
Karanam Apoorva Prakash ${ }^{1}$, Shashikala K ${ }^{2}$, Vanamala ${ }^{3}$ \\ ${ }^{1}$ Post Graduate Student, ${ }^{2}$ Professor, ${ }^{3}$ Reader Department of Conservative Dentistry and Endodontics, \\ D.A.P.M.R.V Dental College, Bangalore
}

\begin{abstract}
:
Aim: This clinical case report describes the rare occurrence of the bayonet shaped maxillary central incisor and its endodontic management.

Background: Knowledge of the normal anatomy of the root canal and its variations is very essential before commencement of endodontic therapy. Root curvatures are very commonly seen and one such challenge to endodontist is a S-shaped or bayonet shaped canal.

Case Description: A 21 year old male patient reported with chief complaint of broken tooth in upper front region. Clinical examination revealed fractured 21 and radiographic examination revealed periapical radiolucency with bayonet shaped canal and prior initiated root canal treatment. Modification of access opening was done, cleaning and shaping was done using Ni-Ti files and canal was obturated.

Clinical significance: Careful interpretation of intra oral periapical radiographs and proper instrumentation techniques minimizes the procedural errors and helps in achieving a successful outcome of the treatment.

Keywords: Bayonet shaped canal, maxillary central incisor, Ni-Ti files.

\section{Introduction}

A straight root and root canal is uncommon to observe as most teeth exhibits some degree of curvature in different planes. ${ }^{1,2}$ Root canal curvatures may be bayonet shaped, sickle shaped, or a apical, gradual and a dilacerated curve. Proper cleaning and shaping of the root canal ensures the success of endodontic therapy. In clinical situations with root canal curvatures, procedural errors such as fractured instruments, ledges, zip and elbow creations may not allow for the complete disinfection leading to endodontic failure. Identification of such variations is essential as it helps in modifying the treatment and results in successful outcome. ${ }^{3}$ This case report illustrates a rare occurrence of bayonet shaped maxillary central incisor and its endodontic management.
\end{abstract}

\section{Case Report}

A 21 year old male patient reported to the department of conservative dentistry and endodontics with the chief complaint of broken upper front tooth with history of trauma 10 years ago. His medical history was non contributory. The clinical examination revealed fractured upper left incisor(21) with prior initiated root canal treatment and the tooth was tender to percussion. Intra oral periapical radiograph revealed bayonet shaped root canal system with periapical radiolucency(figure 1). A diagnosis of prior initiated root canal therapy with chronic periapical abscess was made and the treatment plan was formulated. Written consent was taken and tooth was isolated using rubber dam. As soon as the temporary restoration was removed there was the presence pus discharge with foul odour. Modification of access opening was done with \#3 gates glidden drills, canal patency was established and working length determination was done using \#15 $\mathrm{Ni}$-Ti file (figure2). Ni-Ti files were used for cleaning and shaping ,root canals were alternatively irrigated with $17 \%$ EDTA, 3\% sodium hypochlorite and normal saline. Final rinse was done with $2 \%$ chlorhexidine. Canal was dried and interappointment calcium hydroxide intracanal medicament was placed for a period of 7 days. In the next visit, the tooth was asymptomatic and the canal was dry. The canal was then flushed with irrigating solutions to remove the remnants of intracanal medicament and was dried with absorbent points. Obturation was done with gutta-percha and zinc oxide eugenol sealer using lateral condensation technique (figure $3 \& 4$ ). Post endodontic restoration was done using composite.

\section{Discussion}

Parolia etal described dilacerations as a sudden change in the axial inclination or curve in crown or root of a tooth. Mechanical trauma to the deciduous tooth is considered as the most common cause and other contributing factors include ectopic development of the tooth germ, presence of infection, scar or tumour, developmental anomaly, lack of space, syndrome and hereditary factors. If a tooth is doubly affected it is called as bayonet dilaceration. ${ }^{4}$ 
Khandelwal etal suggested that a preoperative radiograph taken in $20^{\circ}$ mesial or distal projection helps in detecting the morphology and anatomy of the root canal system. ${ }^{5}$ Determining the root curvature will allow for the maintenance of the continuous tapered shapes and prevents structural damage of the endodontic instruments. Various authors have suggested several methods to determine root canal curvature. Schneider performed pioneering work on canal angulation and named according to the degree of curvature as straight $5^{\circ}$ moderate $10^{\circ}$ to $20^{\circ}$ severe as $25^{\circ}$ to $70^{\circ} .^{6}$ According to Gunday etal, Schneider's technique emphasized canal curvature in coronal region, whereas long axis technique which is described by Hankins etal considered the apical curvature and does not evaluate overall root curvature. ${ }^{7}$ Sadeghi etal reported that the root curvatures determined by measuring canal access angle which was introduced by Gunday etal is more effective and appropriate among the all other methods used. ${ }^{8}$

As S-shaped canal has two curves, with apical curve being very difficult to negotiate, Gutman suggested preflaring the coronal third reduces the angle of curvature thus making the remainder of the canal easy for instrumentation. ${ }^{9}$

Shahnaz etal suggested that instrumentation of curved root canals might result in formation of the ledges, blockage of the apical third, loss of working length, apical transformation and perforations. Authors suggested that precurving files or usage of flexible $\mathrm{Ni}$-Ti files decreases the force by means of which straight file has to bend against dentin surface thus minimizing the procedural errors. ${ }^{1}$

Calcium hydroxide intracanal medicament was used because of its actions which are achieved through the ionic dissociation of calcium and hydroxyl ions and their effect on vital tissues and induction of hard tissue deposition and its anti bacterial properties. ${ }^{10}$

Obturation by lateral condensation was done as it is considered as the gold standard technique and is widely advocated. Flexible Ni-Ti spreaders were used as they penetrate to greater depths and distribute forces more evenly. ${ }^{4}$

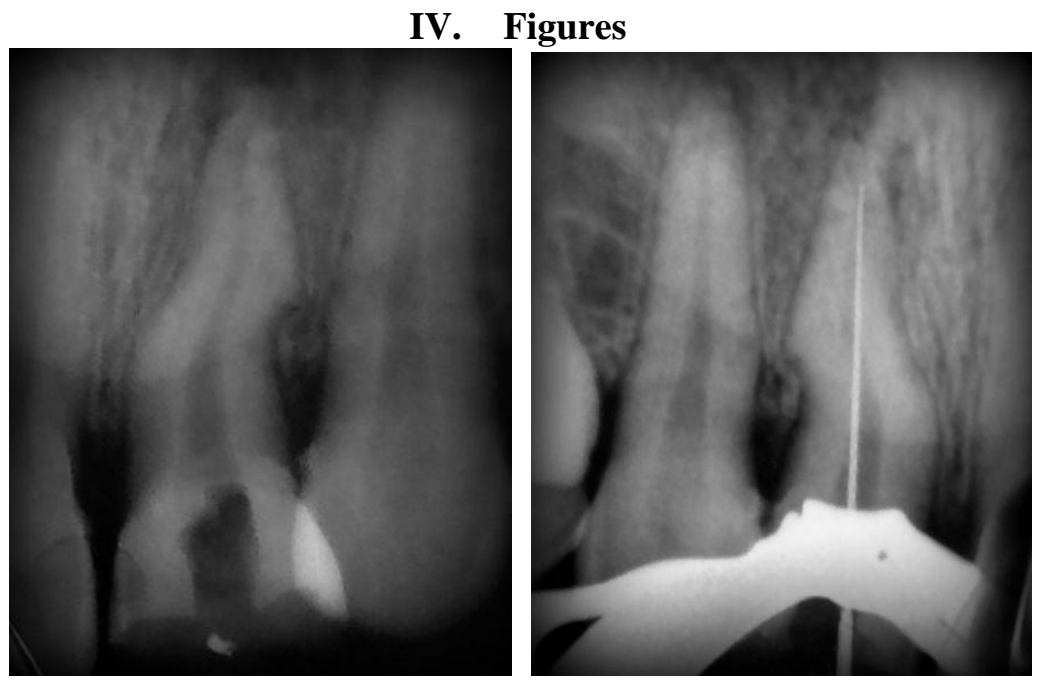

Fig1: Preoperative IOPAR

Fig2: Working length IOPAR

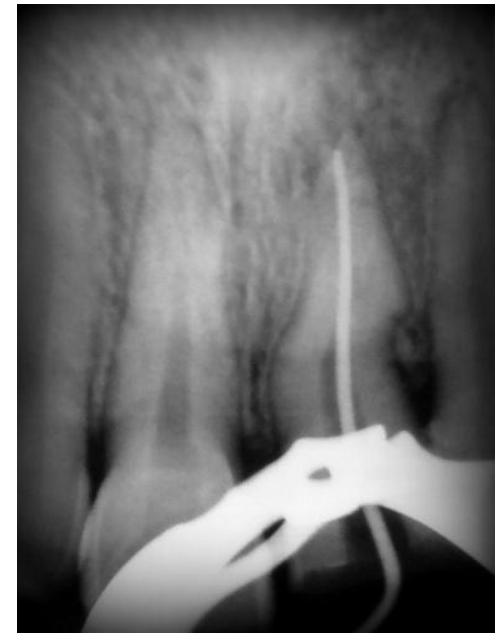

Fig3: Master cone IOPAR

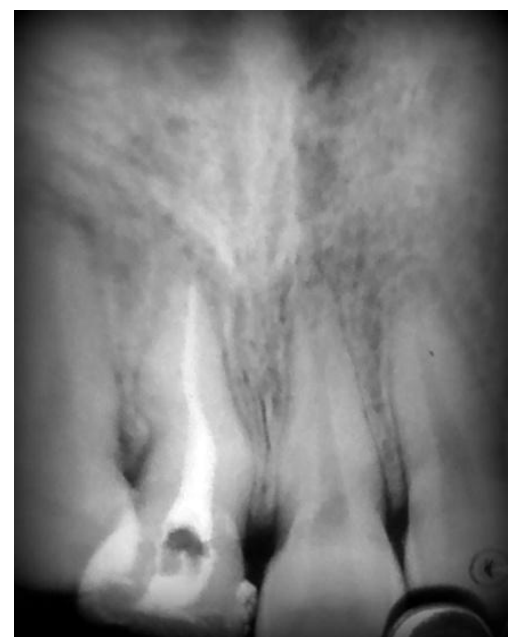

Fig4: Obturation IOPAR 


\section{Conclusion}

Understanding the normal root canal morphologies and its variations helps in identifying and addressing these challenges. Appropriate treatment planning with selection of proper instruments and instrumentation techniques, adhering to basic principles and being aware of the latest technologies of the endodontic therapy helps in managing these root canal complexities and ensures a successful result.

\section{References}

[1]. Shahnaz N, Khalid A, Aijaz H, Ashraf BI, Shah AF. Management of a maxillary second premolar with an S-shaped root canal-An endodontic challenge.

[2]. Cohen S, Burns RC. Pathways of pulp 8th edition. St.Louis: Mosby, 2002, p-94, 243-74, 325-31, 644-45.

[3]. Sakkir N, Thaha KA, Nair MG, Joseph S, Christalin R. Management of Dilacerated and S-shaped Root Canals-An Endodontist's Challenge. Journal of clinical and diagnostic research: JCDR. 2014 Jun;8(6):ZD22.

[4]. Parolia A, Khosla M, Porto IC, Mala K. Endodontic management of dilacerated and bayonet shaped roots. RGO. Revista Gaúcha de Odontologia (Online). 2013 Jun;61(2):269-74.

[5]. Khandelwal V, Nayak UA, Kambalimath HV, Nyak PA. Endodontic Therapy Of A Maxillary Premolar With An S-Shaped Canal.

[6]. Das UK, Mukherjee S, Maiti N. Managing the Risky Curve-A Case Report. International Journal of Clinical Dental Science. 2013 May 12;4(2).

[7]. Günday M, Sazak H, Garip Y. A comparative study of three different root canal curvature measurement techniques and measuring the canal access angle in curved canals. Journal of endodontics. 2005 Nov 30;31(11):796-8.

[8]. Sadeghi S, Poryousef V. A novel approach in assessment of root canal curvature. Iranian endodontic journal. 2010 Feb 10;4(4):1314.

[9]. Guttman JL. Problem solving in endodontics, 3rd edition. Missouri: Mosby- Year book Inc. 1997: p-116.

[10]. Mohammadi Z, Dummer PM. Properties and applications of calcium hydroxide in endodontics and dental traumatology. International endodontic journal. 2011 Aug 1;44(8):697-730. 